\title{
ANALISIS NILAI TAMBAH DAN MARJIN PEMASARAN PISANG MENJADI OLAHAN PISANG (STUDI KASUS PADA INDUSTRI KECIL "SRIKANDI") DI KELURAHAN DANGDEUR KECAMATAN SUBANG KABUPATEN SUBANG JAWA BARAT
}

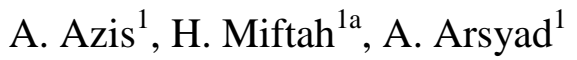 \\ ${ }^{1}$ Jurusan Agribisnis, Fakultas Pertanian Universitas Djuanda Bogor \\ Jl Tol Ciawi No. 1 PO Box 35 Ciawi Bogor 16720, \\ a'Korespondensi: Himmatul Miftah, Telp: 08568049670 E-mail: hmiftah@yahoo.co.id;
}

\begin{abstract}
ABSTRAK
Penelitian ini bertujuan mengetahui keragaan pengolahan pisang menjadi Keripik dan Sale Pisang, nilai tambah serta marjin pemasaran. Pengambilan data dilaksanakan di Kelurahan Dangdeur Kecamatan Subang dari bulan Agustus 2014 sampai September 2014. Metode penelitian menggunakan analisis deskriptif untuk menjelaskan keragaan pengolahan pisang, analisis nilai tambah menggunakan Analisis Hayami, marjin pemasaran menggunakan analisis marjin pemasaran. Hasil penelitian menunjukkan keragaan Agroindustri Sale Pisang Industri Kecil "Srikandi" terdiri dari pengadaan bahan baku pisang dan pengolahan pisang. Nilai tambah dari pengolahan pisang menjadi Keripik Pisang adalah Rp2.607,53 per kg dengan rasio 27,04 persen yang tergolong bernilai tambah sedang yaitu 15-40\%. Nilai Tambah yang diperoleh dari pengolahan pisang menjadi Sale Pisang adalah Rp3.217,91 per $\mathrm{kg}$ dengan rasio 42,27 persen, ini menunjukkan nilai tambah usaha pengolahan pisang menjadi Sale Pisang berkategori tinggi, di atas $40 \%$. Harga jual Keripik Pisang di tingkat produsen (Industri Kecil "Srikandi") Rp40.000,00. Pada saluran pemasaran tingkat I didapatkan margin Rp17.542,96. Pada saluran II pengecer tetap membeli Keripik Pisang ke produsen seharga Rp40.000,00, marjin yang didapat adalah Rp10.000,00. Harga jual Sale Pisang di tingkat produsen Rp40.000,00. Pada saluran pemasaran I, marjin yang didapat Rp24.507,62. Pada saluran II pengecer tetap membeli Sale Pisang ke produsen seharga Rp40.000,00. Marjin yang didapat adalah Rp 10.000,00.
\end{abstract}

Kata kunci: Keragaan, Nilai Tambah, Marjin Pemasaran, Keripik Pisang, Sale Pisang 


\section{PENDAHULUAN}

Kabupaten Subang merupakan salah satu sentra produksi tanaman pisang di Jawa Barat.Tahun 2011 tercatat produksinya 1.233 .463 kuintal di Subang (Dinas Pertanian Pangan Jawa Barat, 2011). Produksi pisang dimanfaatkan guna memperoleh nilai tambah melalui pengolahan pisang menjadi produk olahan, namun demikian belum dikelahui berapa besar nilai tambahnya dan kontribusi tenaga kerja dalam memperoleh nilai tambah produk.

Tujuan penelitian untuk mengetahui keragaan proses pengolahan pisang menjadi Keripik Pisang dan Sale Pisang, pada Industri Kecil mengetahui nilai tambah dan marjin pemasaran dari pengolahan pisang menjadi Keripik Pisang dan Sale Pisang.

\section{BAHAN DAN METODE}

Penelitian dilaksanakan pada industri kecil "Srikandi" di Kelurahan Dangdeur Kecamatan Subang, Kabupaten Subang. Penelitian ini dimulai Agustus 2014 sampai dengan September 2014. Pemilihan lokasi penelitian dilakukan secara purposif dengan responden anggota dari Industri Kecil "Srikandi". Metode penelitian yang digunakan adalah analisis deskriptif untuk menjelaskan keragaan usaha pengolahan pisang menjadi Keripik Pisang dan Sale Pisang, analisis nilai tambah menggunakan Metode Hayami, dan untuk menghitung marjin pemasaran dihitung dengan menggunakan analisis marjin pemasaran.

\section{HASIL DAN PEMBAHASAN}

Industri Kecil "Srikandi" didirikan pada bulan Juli 2014 anggotanya ibu-ibu rumah tangga yang berdomisili di Dusun Bunder Kelurahan Dangdeur Kecamatan Subang Kabupaten Subang. Anggota berjumlah 9 (sembilan) orang, terdiri dari 3 (tiga) orang mengolah pisang menjadi Keripik Pisang, 2 (dua) orang anggota lagi mengolah pisang menjadi Sale Pisang, sedangkan 4 anggota lainnya mengolah produk lain yaitu Keripik Singkong.

Kegiatan produktif didukung oleh peralatan lengkap untuk mengolah pisang. Bahan baku, bahan penolong, bahan bakar, teknologi dan tenaga kerja cukup dalam mendukung keberhasilan usaha. Diagram alur pengolahan Keripik Pisang disajikan pada Gambar 1.

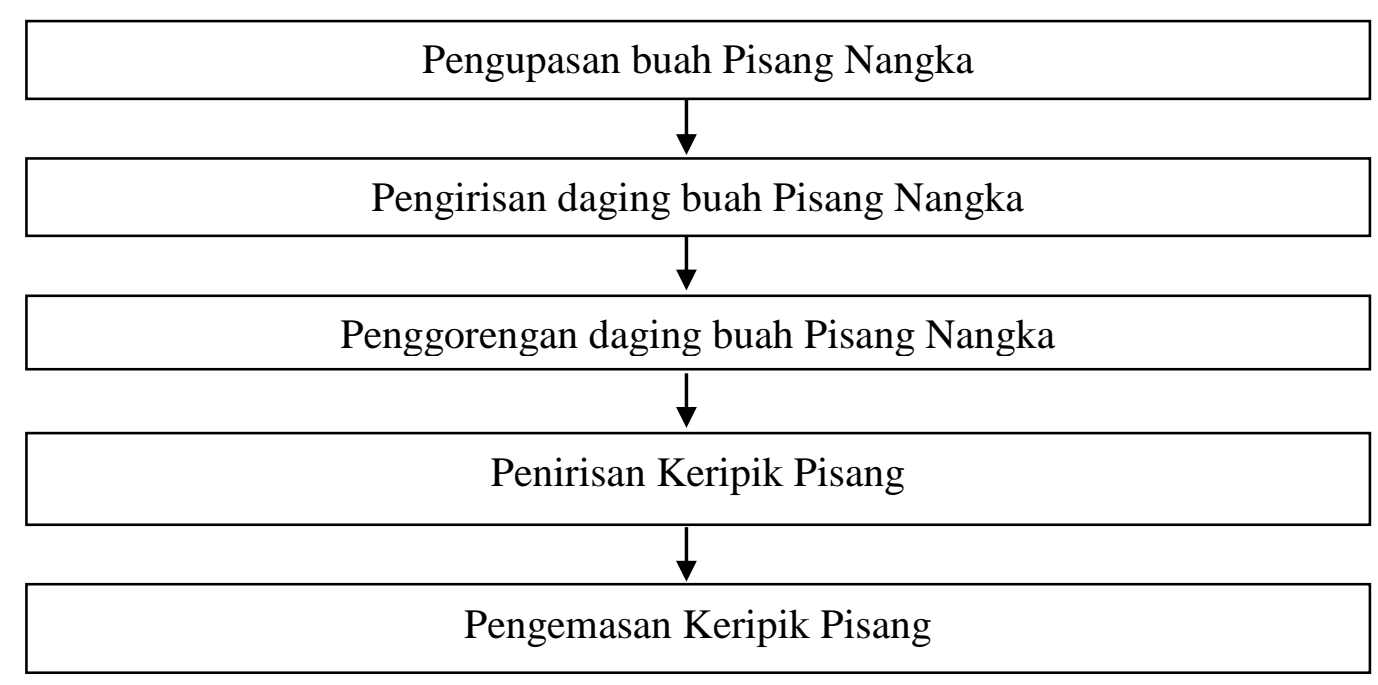

Gambar 1. Diagram Alur Pengolahan Keripik Pisang

Adapun diagram alur pengolahan Sale Pisang pada skala kecil ini dimulai dari : 1) proses sortasi buah pisang kapok, (2) pengupasan (3) pengirisan buah pisang kapok, (4) penjemuran buah pisang kapok, (5) pencampuran terigu dengan daging buah pisang kapok, (6) penggorengan dan pengemasan buah pisang kapok 
Analisis Nilai Tambah Usaha Keripik Pisang dan Sale Pisang

Nilai Tambah pengolahan kripik pisan dan sale pisang disajikan pada tabel 1. Nilai faktor konversi yaitu perbandingan antara output dengan input. Nilai faktor konversi untuk Keripik Pisang adalah jumlah output dibagi dengan input yang digunakan. Nilai faktor konversi untuk Keripik Pisang adalah sebesar 0,24. Nilai faktor konversi menunjukkan bahwa setiap $100 \mathrm{~kg}$ pisang mampu menghasilkan 24,11 $\mathrm{kg}$ Keripik Pisang. Nilai faktor konversi untuk Sale Pisang adalah jumlah output dibagi dengan input yang digunakan. Ratarata nilai faktor konversi untuk Sale Pisang adalah sebesar 0,19. Nilai faktor konversi menunjukkan bahwa setiap $100 \mathrm{~kg}$ pisang mampu menghasilkan $19,03 \mathrm{~kg}$ Sale Pisang.

Tabel 1. Analisis Nilai Tambah Usaha Keripik Pisang dan Sale Pisang (dalam 100 kg input Tahun 2014, pada Industri Kecil Srikandi)

\begin{tabular}{|c|c|c|c|c|}
\hline \multirow{2}{*}{ No } & \multirow{2}{*}{ Variabel Ouput, Input, dan Harga } & \multicolumn{3}{|c|}{ Perhitungan } \\
\hline & & Kode & Keripik & Sale \\
\hline 1 & Output $(\mathrm{Kg} /$ proses produksi) & $\mathrm{A}$ & 24,11 & 19,03 \\
\hline 2 & Input pisang (Kg/proses produksi) & $\mathrm{B}$ & 100 & 100 \\
\hline 3 & Tenaga Kerja (hok/proses produksi) & $\mathrm{C}$ & 7 & 2.6 \\
\hline 4 & Faktor konversi & $\mathrm{D}=\mathrm{A} / \mathrm{B}$ & 0,24 & 0,19 \\
\hline 5 & Koefisien tenaga kerja & $\mathrm{E}=\mathrm{C} / \mathrm{B}$ & 0,070 & 0,026 \\
\hline \multirow[t]{2}{*}{6} & Harga Ouput (Rp/ Kg) & $\mathrm{F}$ & $40.000,00$ & $40.000,00$ \\
\hline & Pendapatan dan Keuntungan & & & \\
\hline 7 & Upah tenaga kerja $(\mathrm{Rp} / \mathrm{HOK})$ & $\mathrm{G}$ & $15.000,00$ & $15.000,00$ \\
\hline 8 & Harga bahan baku $(\mathrm{Rp} / \mathrm{Kg})$ & $\mathrm{H}$ & $4.000,00$ & $2.500,00$ \\
\hline 9 & $\begin{array}{l}\text { Sumbangan input lain (Rp/kg). } \\
\text { Keripik Pisang: Minyak goreng, Mentega, Gas, } \\
\text { Plastik). } \\
\text { (Sale Pisang : Minyak goreng, Tepung Terigu, } \\
\text { Kayu Bakar, plastik) }\end{array}$ & I & $3.036,47$ & $1.894,09$ \\
\hline 10 & Nilai Output $(\mathrm{Rp})$ & $\mathrm{J}=\mathrm{D} \times \mathrm{F}$ & $9.644,00$ & $7.612,00$ \\
\hline \multirow[t]{2}{*}{11} & a. Nilai Tambah $(\mathrm{Rp} / \mathrm{kg})$ & $\mathrm{K}=\mathrm{J}-\mathrm{H}-\mathrm{I}$ & 2.607 .53 & $3.217,91$ \\
\hline & b. Rasio Nilai tambah (\%) & $\mathrm{L}=(\mathrm{K} / \mathrm{J}) \times 100 \%$ & 27,04 & 42,27 \\
\hline \multirow[t]{2}{*}{12} & a. Pendapatan tenaga kerja $(\mathrm{Rp} / \mathrm{kg})$ & $\mathrm{M}=\mathrm{E} \times \mathrm{G}$ & $1.050,00$ & 390,00 \\
\hline & b. Bagian tenaga kerja $(\%)$ & $\mathrm{N}=(\mathrm{M} / \mathrm{K}) \times 100 \%$ & 40,27 & 12,12 \\
\hline \multirow[t]{3}{*}{13} & a. Keuntungan $(\mathrm{Rp} / \mathrm{Kg})$ & $\mathrm{O}=\mathrm{K}-\mathrm{M}$ & $1.557,53$ & $2.827,91$ \\
\hline & b. Tingkat keuntungan (\%) & $\mathrm{P}=(\mathrm{O} / \mathrm{K}) \times 100 \%$ & 59,73 & 87,88 \\
\hline & Balas Jasa untuk Faktor produksi & & & \\
\hline \multirow[t]{4}{*}{14} & $\operatorname{Marjin}(\mathrm{Rp} / \mathrm{Kg})$ & $\mathrm{Q}=\mathrm{J}-\mathrm{H}$ & $5.644,00$ & $5.112,00$ \\
\hline & a. Pendapatan tenaga kerja $(\%)$ & $\mathrm{R}=(\mathrm{M} / \mathrm{Q}) \times 100 \%$ & 18.604 & 7.63 \\
\hline & b. Sumbangan Input Lain (\%) & $\mathrm{S}=(\mathrm{I} / \mathrm{Q}) \times 100 \%$ & 53,80 & 37,05 \\
\hline & c. Keuntungan pengolah (\%) & $\mathrm{T}=(\mathrm{O} / \mathrm{Q}) \times 100 \%$ & 27,60 & 55,32 \\
\hline
\end{tabular}

Nilai koefisien tenaga kerja menunjukkan apakah pelaku usaha sudah atau belum efisien dalam berproduksi. Semakin kecil nilai koefisien tenaga kerja maka semakin efisien pelaku usaha berproduksi. Rata-rata nilai koefisien tenaga kerja pada pengolahan Keripik Pisang adalah sebesar 0,070, hal ini menunjukan bahwa untuk mengolah 100 $\mathrm{kg}$ pisang menjadi $24,11 \mathrm{~kg}$ Keripik Pisang dibutuhkan tenaga kerja 7 HOK. Nilai koefisien tenaga kerja pada pengolahan 
Sale Pisang adalah sebesar 0,026. Hal ini menunjukkan untuk mengolah $100 \mathrm{~kg}$ pisang menjadi $19,03 \mathrm{~kg}$ Sale Pisang dibutuhkan 2,6 HOK. Harga jual Keripik Pisang dan Sale Pisang dari Industri Kecil "Srikandi" di Kelurahan Dangdeur Kecamatan Subang Kabupaten Subang adalah Rp40.000/kg.

\section{Pendapatan dan Keuntungan Usaha Keripik Pisang dan Sale Pisang}

Besarnya pendapatan tenaga kerja per satu kilogram Keripik Pisang diperoleh dari hasil kali antara koefisien tenaga kerja dengan upah tenaga kerja. Besarnya upah tenaga kerja untuk pengolahan Keripik Pisang pada Industri Kecil "Srikandi" adalah Rp15.000/HOK/proses produksi. Sehingga besarnya pendapatan yang diterima oleh tenaga kerja langsung dari pengolahan satu $\mathrm{kg}$ pisang menjadi Keripik Pisang adalah sebesar Rp1.050 per $\mathrm{kg}$ input, dengan bagian tenaga kerja sebesar 40,27 persen dari nilai tambah.

Besarnya pendapatan tenaga kerja per satu kilogram Sale Pisang diperoleh dari hasil kali antara koefisien tenaga kerja dengan upah tenaga kerja. Besarnya upah tenaga kerja untuk pengolahan Sale Pisang pada Industri Kecil "Srikandi" adalah Rp15.000/HOK/proses produksi. Sehingga besarnya pendapatan yang diterima oleh tenaga kerja langsung dari pengolahan satu $\mathrm{kg}$ pisang menjadi Sale Pisang adalah sebesar Rp390 per kg input, dengan bagian tenaga kerja sebesar 12,12 persen dari nilai tambah.

Perhitungan nilai tambah bertujuan untuk mengetahui besarnya nilai tambah dalam satu $\mathrm{kg}$ pisang setelah diolah menjadi Keripik Pisang dan Sale Pisang. Besarnya nilai tambah tergantung pada biaya yang dikeluarkan meliputi biaya pembelian bahan baku dan sumbangan input lain. Sumbangan input lain terdiri dari seluruh biaya variabel kecuali biaya bahan baku dan upah tenaga kerja.

Hasil perhitungan nilai tambah yang diperoleh dari pengolahan pisang menjadi Keripik Pisang menunjukkan bahwa besarnya nilai tambah pada pengolah Keripik Pisang adalah sebesar Rp2.607,53 per $\mathrm{kg}$. Besarnya nilai tambah pada pengolah Sale Pisang adalah sebesar Rp3.217,91 per kg.

Rasio nilai tambah yaitu perbandingan antara nilai tambah dengan output. Rasio nilai tambah pisang per proses produksi pada pengolah Keripik Pisang adalah sebesar 27,04 persen. Keuntungan yang diperoleh dari proses pembuatan Keripik Pisang adalah Rp1.557,53 per $\mathrm{kg}$ atau 59,73 persen dari nilai tambah produk.

Rasio nilai tambah pisang per proses produksi pada pengolah Sale Pisang adalah sebesar 42,27 persen. Keuntungan yang diperoleh dari proses pembuatan Sale Pisang adalah Rp2.827,91 per $\mathrm{kg}$ atau 87,88 persen dari nilai tambah produk.

Hasil perhitungan nilai tambah yang diperoleh dari pengolahan pisang menjadi Keripik Pisang pada Industri Kecil "Srikandi" adalah sebesar Rp2.607,53 per $\mathrm{kg}$ dengan rasio sebesar 27,04 persen. Hal ini menunjukkan bahwa usaha pengolahan pisang menjadi Keripik Pisang Industri Kecil "Srikandi" tergolong dalam kategori bernilai tambah sedang, yang dalam standar Metode Hayami memiliki nilai rasio di bawah $15-40 \%$. Sedangkan nilai tambah yang diperoleh dari pengolahan pisang menjadi Sale Pisang Industri Kecil "Srikandi" tergolong dalam kategori bernilai tambah tinggi yaitu di atas 40 persen dengan rasio sebesar 42,27 persen dan nilai tambah sebesar Rp3.217,91 per $\mathrm{kg}$.

\section{Balas Jasa Untuk Faktor Produksi}

Balas jasa faktor produksi terdiri atas balas jasa untuk faktor produksi tenaga kerja, input lain, dan tingkat keuntungan. Marjin merupakan selisih harga atau nilai produk dengan nilai input bahan baku. Marjin akan didistribusikan untuk imbalan tenaga kerja, sumbangan input lain dan keuntungan perusahaan.

Marjin dari produksi Keripik Pisang adalah sebesar Rp5.644,00 per kg pisang, 
yang terdiri atas 18,604 persen pendapatan tenaga kerja, 53,80 persen sumbangan input lain dan 27,60 persen keuntungan pengolah Keripik Pisang. Rata-rata marjin dari produksi Sale Pisang adalah sebesar Rp5.112,00 per kg pisang, yang terdiri atas 7,63 persen pendapatan tenaga kerja, 39,01 persen sumbangan input lain dan 53,36 persen keuntungan pengolah Sale Pisang.
Nilai output Keripik Pisang pada penelitian ini adalah $24,11 \mathrm{~kg}$ dengan harga Rp40.000 kg. Sedangkan Nilai output Sale Pisang adalah 19,03 kg dengan harga Rp40.000/kg. Pendapatan Tenaga Kerja Langsung untuk satu kali proses produksi pada pengolahan Keripik Pisang adalah sebesar Rp1.050,00.dapat dilihat pada Tabel 2.

Tabel 2. Pendapatan Tenaga Kerja Langsung pada Usaha Keripik

\begin{tabular}{lccc}
\hline \multicolumn{1}{c}{ Pekerjaan } & $\begin{array}{c}\text { Jumlah Tenaga } \\
\text { Kerja (orang) }\end{array}$ & $\begin{array}{c}\text { Upah } \\
\text { (Rp/orang) }\end{array}$ & $\begin{array}{c}\text { Total } \\
\text { (Rp) }\end{array}$ \\
\hline Mengupas & 2 & $15.000,00$ & $30.000,00$ \\
Menggoreng & 2 & $15.000,00$ & $30.000,00$ \\
Mengiris \& Mengemas & 3 & $15.000,00$ & $45.000,00$ \\
Total & 7 & & $105.000,00$ \\
Rata-rata & & & $15.000,00$ \\
\hline
\end{tabular}

Pendapatan Tenaga Kerja Langsung untuk satu kali proses produksi pada pengolahan Sale Pisang adalah sebesar Rp390 untuk satu kali proses produksi, dapat dilihat pada Tabel 2 . Upah tenaga kerja untuk setiap kilogram input Bahan Baku Pisang yang diolah menjadi Sale Pisang adalah Rp15.000/per proses produksi/HOK.

Tabel 3. Rata-rata Pendapatan Tenaga Kerja Langsung pada Usaha Sale Pisang

\begin{tabular}{lccc}
\hline \multicolumn{1}{c}{ Pekerjaan } & $\begin{array}{c}\text { Jumlah Tenaga } \\
\text { Kerja (orang) }\end{array}$ & $\begin{array}{c}\text { Upah } \\
\text { (Rp/orang) }\end{array}$ & Total (Rp) \\
\hline Mengupas, Mengiris, Menjemur, & 1 & $15.000,00$ & $15.000,00$ \\
Menggoreng dan Mengemas & 1 & $15.000,00$ & $15.000,00$ \\
Total & 2 & & $30.000,00$ \\
Rata-rata & & & $15.000,00$ \\
\hline
\end{tabular}

Sumbangan input lain untuk Keripik Pisang meliputi bahan penolong, bahan bakar, dan pengemas. Bahan penolong adalah minyak goreng dan mentega.Bahan bakar adalah gas, bahan pengemasan adalah plastik pembungkus.

Sumbangan input lain untuk Sale Pisang meliputi bahan penolong, bahan bakar, dan pengemas. Bahan penolong adalah minyak goreng dan tepung terigu. Bahan bakar adalah kayu bakar, bahan pengemasan adalah plastik pembungkus. Format perhitungan sumbangan input lain adalah sebagai berikut :
Sumbangan Input Lain $=\frac{\text { Total Sumbangan Input Lain }}{\text { Jumlah Bahan Baku }}$

Harga bahan baku/input untuk Keripik Pisang adalah Rp4.000 per kg, sedangkan harga bahan baku/input untuk Sale Pisang adalah Rp2.500 per kg. Perbedaan ini terjadi karena bahan baku pisang untuk Keripik Pisang dibeli di pasar sehingga harganya lebih mahal, sedangkan bahan baku pisang untuk Sale Pisang dibeli di bandar sehingga harganya lebih murah. 
Tabel 4. Rata-rata Total Sumbangan Input Lain Usaha Keripik Pisang

\begin{tabular}{lccccr}
\hline \multicolumn{1}{c}{ Bahan } & $\begin{array}{c}\text { Kuantitas } \\
(\mathbf{k g})\end{array}$ & Harga & $\begin{array}{c}\text { Proses } \\
\text { Produksi }\end{array}$ & $\begin{array}{c}\text { Rata-rata } \\
\text { total }(\mathbf{k g})\end{array}$ & $\begin{array}{c}\text { Rata-rata harga } \\
\text { dalam 1 x proses } \\
\text { produksi }\end{array}$ \\
\hline Minyak Bimoli & 18 & 14.000 & 4 & 4,50 & $148.235,3$ \\
Mentega & 1 & 3.000 & 4 & 0,18 & 1.235 \\
Plastik (pack) & 3,4 & 10.000 & 4 & 0,85 & 20.059 \\
Gas & 12 & 19.000 & 4 & 3 & $134.117,6$ \\
Jumlah total & & & & & $303.647,014$ \\
\hline
\end{tabular}

Rata-rata total sumbangan input lain untuk pengolahan Keripik Pisang Industri Kecil "Srikandi" adalah Rp303.647,014 per proses produksi, untuk bahan baku sebanyak $100 \mathrm{~kg}$ pisang yang diolah menjadi Keripik Pisang, maka nilai sumbangan input lain yang didapat pada Industri Kecil "Srikandi" adalah sebesar Rp3.036,47/kg yang diperoleh dari hasil bagi rata-rata total sumbangan input lain sebesar Rp303.647,047 dengan jumlah bahan baku Keripik Pisang sebesar $100 \mathrm{~kg}$.

Tabel 5. Perhitungan Rata-rata Total Sumbangan Input Lain Usaha Sale Pisang

\begin{tabular}{lccccc}
\hline \multicolumn{1}{c}{ Bahan } & $\begin{array}{c}\text { Kuantitas } \\
(\mathbf{k g})\end{array}$ & Harga & $\begin{array}{c}\text { Proses } \\
\text { Produksi }\end{array}$ & $\begin{array}{c}\text { Rata-Rata } \\
\text { Total }(\mathbf{K g})\end{array}$ & $\begin{array}{c}\text { Rata-rata harga dalam } \\
\mathbf{1} \text { x proses produksi }\end{array}$ \\
\hline Terigu & 19 & 9.000 & 2 & 9,50 & $55.161,29$ \\
Minyak goreng & 18,5 & 16.000 & 2 & 9,25 & $95.483,87$ \\
Kayu Bakar (ikat) & 12 & 10.000 & 2 & 6,00 & $38.709,68$ \\
Plastik (pack) & 13 & 17.000 & 2 & 7 & 54,52 \\
Jumlah total & & & & & $189.409,356$ \\
\hline
\end{tabular}

Rata-rata total sumbangan input lain untuk pengolahan Sale Pisang Industri Kecil Srikandi adalah Rp189.409,356 per proses produksi, untuk bahan baku sebanyak $100 \mathrm{~kg}$ pisang yang diolah menjadi Sale Pisang, maka nilai sumbangan input lain yang didapat Industri Kecil "Srikandi" adalah sebesar Rp1.894,09/kg yang diperoleh dari hasil bagi rata-rata total sumbangan input lain sebesar Rp dengan jumlah bahan baku Sale Pisang sebesar $100 \mathrm{~kg}$.

\section{Saluran dan Marjin Pemasaran Usaha Keripik Pisang dan Sale Pisang}

Pemasaran Keripik Pisang dan Sale Pisang Industri Kecil Srikandi dapat dilihat pada Gambar 3.

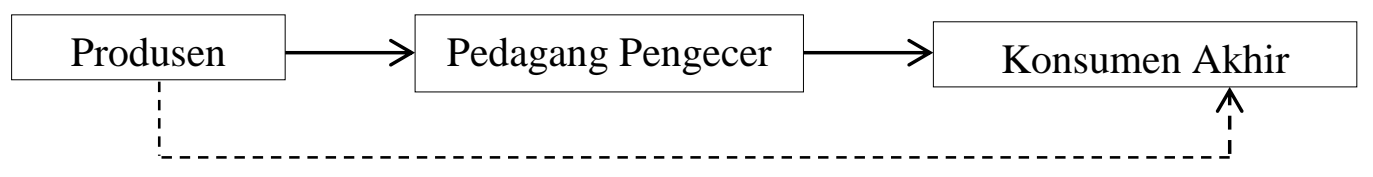

Keterangan :

---.. = Saluran 1

Produsen $\longrightarrow$ Konsumen Akhir

Saluran pemasaran 1, produsen dalam hal ini adalah Industri Kecil "Srikandi" didatangi langsung oleh konsumen untuk membeli Keripik Pisang dan Sale Pisang sehingga tidak ada biaya pemasaran yang dikeluarkan. 


\section{$\rightarrow=$ Saluran $2 \quad$ Produsen $\rightarrow$ Pedagang Pengecer $\rightarrow$ Konsumen Akhir}

Gambar 5. Saluran Pemasaran Keripik Pisang dan Sale Pisang

Pada saluran pemasaran 2 ini dilakukan oleh pedagang pengecer (responden) di Kelurahan Dangdeur yang langsung memasarkan Keripik Pisang dan Sale Pisang kepada konsumen. Hal ini karena pedagang pengecer langsung datang ke rumah produksi Industri Kecil "Srikandi" untuk membeli Keripik Pisang dan Sale Pisanguntuk dijual langsung kepada konsumen.

Biaya produksi Keripik Pisang merupakan total biaya pengolahan, didapati sebesar 22.457,04/kg yang diperoleh dari pembagian total biaya pengolahan Keripik Pisang sebesar Rp541.439,25/kg dengan jumlah output Keripik Pisang (kg) sebanyak 24,11 kg. Biaya produksi Sale Pisang merupakan total biaya pengolahan, didapati sebesar $15.492,38 / \mathrm{kg}$ yang diperoleh dari pembagian total biaya pengolahan Sale Pisang sebesar Rp294.819,92/kg dengan jumlah output Sale Pisang (kg) sebanyak $19,03 \mathrm{~kg}$.

Tabel 6. Biaya, Keuntungan, dan Marjin Pemasaran Usaha Keripik Pisang

\begin{tabular}{|c|c|c|c|}
\hline No. & Lembaga Pemasaran keripik & Saluran $1(\mathrm{Rp})$ & Saluran $2(\mathrm{Rp})$ \\
\hline \multirow[t]{6}{*}{1} & Produsen & & \\
\hline & Biaya Produksi & $22.457,04$ & $22.457,04$ \\
\hline & Harga Jual & $40.000,00$ & $40.000,00$ \\
\hline & Marjin & $17.542,96$ & $17.542,96$ \\
\hline & Biaya (Pengemasan) & 145,17 & 145,17 \\
\hline & Keuntungan & $17.397,79$ & $17.397,79$ \\
\hline \multirow[t]{6}{*}{2} & Pengecer Tetap & & \\
\hline & Harga beli & & $40.000,00$ \\
\hline & Harga jual & & $50.000,00$ \\
\hline & Marjin & & $10.000,00$ \\
\hline & Biaya (Pengemasan,Transportasi) & & $1.463,88$ \\
\hline & Keuntungan & & $8.536,12$ \\
\hline \multirow[t]{3}{*}{3} & Biaya Total & 492,00 & $1.609,05$ \\
\hline & Marjin Total & $20.434,00$ & $27.542,96$ \\
\hline & keuntungan total & $17.397,79$ & $25.933,91$ \\
\hline
\end{tabular}

Sumber : Data Primer Diolah, 2014

Harga jual di tingkat produsen (Industri Kecil "Srikandi”) Rp40.000. Pada saluran pemasaran tingkat I konsumen membeli langsung ke produsen dengan harga Rp40.000 sehingga marjin yang didapat sebesar Rp24.607,06 sedangkan keuntungan yang diperoleh dari penjualan Keripik Pisang sebesar Rp24.488,40, keuntungan ini diperoleh dari pengurangan marjin dengan biaya pengemasan (plastik) sebesar Rp118,66, sehingga keuntungan total yang diperoleh dalam satu $\mathrm{kg}$ Keripik Pisang sebesar Rp16.028,34. Sedangkan Pada saluran II pengecer tetap membeli Keripik Pisang ke produsen dengan harga Rp40.000, pengecer tetap menjual produk tersebut ke konsumen dengan harga Rp50.000 sehingga marjin yang didapat sebesar Rp10.000. Keuntungan yang diperoleh 
dari penjualan Keripik Pisang sebesar Rp8.536,12, keuntungan ini diperoleh dari pengurangan marjin dengan biaya transportasi sebesar Rp1.463,88 sehingga keuntungan total yang diperoleh dalam satu kg Keripik Pisang sebesar Rp25.933,91.

Perbedaan harga jual dari lembaga satu dengan lembaga yang lainnya sampai ke tingkat konsumen akhir disebabkan karena lembaga pemasaran melakukan fungsi-fungsi pemasaran yang berbedabeda pula. Salah satu faktor yang mempengaruhi marjin atau selisih harga antara harga jual di tingkat produsen (Industri Kecil "Srikandi") dengan harga beli di tingkat pedagang pengecer tetap adalah adanya lembaga pemasaran yang terlibat, yaitu pedagang pengecer kelurahan. Pedagang pengecer kelurahan mengambil keuntungan dalam menyalurkan produk Keripik Pisang dan Sale Pisang agar dapat sampai ke tangan konsumen sehingga harga jualnya berbeda.

Tabel 6 menunjukkan bahwa setiap lembaga yang terlibat dalam pemasaran Keripik Pisang dan Sale Pisang Usaha Kecil "Srikandi" baik Produsen dan Pengecer Tetap telah menetapkan jumlah harga yang harus dibayarkan oleh konsumen berdasarkan atas perhitungan setiap biaya yang telah dikeluarkan untuk memasarkan produk agar sampai ke tangan konsumen. Selanjutnya dari biaya tersebut lembaga pemasaran mengambil selisih untuk mendapatkan keuntungan dari hasil penjualan.

Tabel 7. Biaya, Keuntungan, dan Marjin Pemasaran Usaha Sale Pisang

\begin{tabular}{clrc}
\hline No & Lembaga Pemasaran sale & Saluran 1 (Rp) & Saluran 2 (Rp) \\
\hline 1 & Produsen & & \\
& Biaya Produksi & $15.492,38$ & $15.492,38$ \\
& Harga Jual & $40.000,00$ & $40.000,00$ \\
& Marjin & $24.507,62$ & $24.507,62$ \\
& Biaya (Pengemasan) & 183,92 & 183,92 \\
& Keuntungan & $24.323,70$ & $24.323,70$ \\
2 & & \\
& Pengecer Tetap & & $40.000,00$ \\
& Harga beli & & $50.000,00$ \\
& Harga jual & & $10.000,00$ \\
& Marjin & & 508,53 \\
& Biaya & & $9.491,47$ \\
& (Pengemasan,Transportasi) & & 692,45 \\
& Keuntungan & & $34.507,62$ \\
Biaya Total & 183,92 & $33.815,17$ \\
\hline
\end{tabular}

Sumber : Data Primer Diolah, 2014.

Harga jual di tingkat produsen (Industri Kecil "Srikandi") Rp40.000. Pada saluran pemasaran tingkat I konsumen membeli langsung ke produsen dengan harga Rp40.000 sehingga marjin yang didapat sebesar Rp24.507,62 sedangkan keuntungan yang diperoleh dari penjualan Sale Pisang sebesar
Rp24.323,70, keuntungan ini diperoleh dari pengurangan marjin dengan biaya pengemasan (plastik) sebesar Rp183,92, sehingga keuntungan total yang diperoleh dalam satu kg Sale Pisang sebesar Rp24.323,70. Sedangkan pada saluran II pengecer tetap membeli Sale Pisang ke produsen dengan harga Rp40.000, 
pengecer tetap menjual produk tersebut ke konsumen dengan harga Rp50.000 sehingga marjin yang didapat sebesar Rp10.000. Keuntungan yang diperoleh dari penjualan Sale Pisang sebesar Rp9.491,47, keuntungan ini diperoleh dari pengurangan marjin dengan biaya transportasi sebesar Rp508,53 sehingga keuntungan total yang diperoleh dalam satu kg Keripik Pisang sebesar Rp33.815,17.

Selisih harga antara harga jual di tingkat produsen (Industri Kecil "Srikandi") dengan harga beli di tingkat pedagang pengecer tetap dipengaruhi oleh adanya lembaga pemasaran yang terlibat, yaitu pedagang pengecer kelurahan. Karena pedagang pengecer kelurahan mengambil keuntungan dalam menyalurkan produk Keripik Pisang agar dapat sampai ke tangan konsumen.

Tabel 7 menunjukkan bahwa setiap lembaga yang terlibat dalam pemasaran Keripik Pisang dan Sale Pisang Usaha Kecil "Srikandi" baik Produsen dan Pengecer Tetap telah menetapkan jumlah harga yang harus dibayarkan oleh konsumen berdasarkan atas perhitungan setiap biaya yang telah dikeluarkan untuk memasarkan produk agar sampai ke tangan konsumen. Selanjutnya dari biaya tersebut lembaga pemasaran mengambil selisih untuk mendapatkan keuntungan dari hasil penjualan.

\section{KESIMPULAN DAN IMPLIKASI KEBIJAKAN}

\section{Kesimpulan}

Kesimpulan pada penelitian ini adalah :

1. Industri Kecil "Srikandi"

Beranggotakan ibu-ibu rumah tangga yang berdomisili di Dusun Bunder Kelurahan Dangdeur Kecamatan Subang Kabupaten Subang. Anggota berjumlah 9 (sembilan) orang. Kegiatan produktif didukung oleh peralatan lengkap untuk mengolah pisang. Bahan baku, bahan penolong, bahan bakar, teknologi dan tenaga kerja cukup dalam mendukung keberhasilan usaha.
2. Kegiatan pengolahan per kilogram Keripik Pisang dan Sale Pisang menguntungkan, yaitu Rp1.557,53 untuk Keripik Pisang dan Rp2.827,91 untuk Sale Pisang.

3. Usaha pengolahan pisang menjadi Keripik Pisang bernilai tambah sedang sebesar 27,04 \%, yang dalam standar Metode Hayami memiliki nilai rasio berkisar antara 15-40\%. Sedangkan pengolahan pisang menjadi Sale Pisang tergolong dalam kategori bernilai tambah tinggi besar yaitu 42,27\%.

4. Saluran pemasaran terdapat dua saluran yaitu saluran I dari produsen langsung kepada konsumen akhir, dan saluran II dari produsen ke pedagang pengecer lalu ke konsumen akhir. Marjin Pemasaran tingkat I pada produk olahan Pisang menjadi Keripik Pisang sebesar Rp17.542,96 sedangkan Marjin Pemasaran tingkat II pada produk olahan PIsang menjadi Keripik Pisang sebesar Rp10.000,00. Marjin Pemasaran tingkat I pada produk olahan Pisang menjadi Sale Pisang sebesar Rp24.507,62 sedangkan Marjin Pemasaran tingkat II pada produk olahan PIsang menjadi Sale Pisang sebesar Rp10.000,00

\section{Implikasi Kebijakan}

Berdasarkan hasil penelitian dan pembahasan, saran yang dapat diberikan oleh penulis adalah sebagai berikut :

1. Nilai tambah ditingkatkan melalui efisiensi dalam kegiatan proses produksi seperti pengurangan tenaga kerja dengan diiringi pengoptimalan pembagian pekerjaan pada kegiatan proses produksi.

2. Pemasaran perlu diperluas dengan melakukan kegiatan promosi secara personal maupun oleh kelompok"Srikandi," dan

3. Variasi Produk perlu dikembangkan melalui inovasi dan modifikasi bentuk, rasa, dan warna untuk meningkatkan kualitas dan keberagaman karakteristik produk. 



\section{DAFTAR PUSTAKA}

Andriati, Weni. 2011. Keragaan Agroindustri Minyak Akar Wangi. [Skripsi] Jurusan Sosial Ekonomi, Fakultas Pertanian Universitas Padjadjaran.

Aristanto. 1996. Pemberdayaan Usaha Kecil. [Science Journal]No : 25 Desember. Malang: Universitas Merdeka.

Asmarantaka, R.W. 1999. Pemasaran Pertanian. Fakultas Pertanian. Universitas Djuanda. Bogor.

Hayami, Y. 1987. Agricultural Marketing and Processing in Upland Java, a Perspective From Sunda Village. Bogor: CGPRT Center.

Hidayat, T. Riyan. 2009. Analisis nilai tambah pisang awak (musa paradisiaca, 1) dan distribusinya pada perusahaan "na raseuki" dan "berkah" di Kabupaten Bireun, Pemerintah Aceh. [Skripsi] Institut Pertanian Bogor.

Kotler, Philip, dan Gary Armstrong. 2008. Prinsip-prinsip Pemasaran Edisi 12 Jilid 1. Jakarta: Erlangga

Kotler, P. 1995. Manajemen Pemasaran. Jakarta: Salemba Empat.

Limbong, W.H dan Sitorus, P. 1987 Pengantar Tataniaga Pertanian. Ilmu Sosial Ekonomi Pertanian. Bogor: Institut Pertanian Bogor.

Lipsey, G. R., Peter, O. S. dan Douglas, D. P. 1990.Pengantar Mikroekonomi 1 Jilid I. Diterjemahkan oleh Jaka, A.W dan Kirbrandoko. Jakarta: Erlangga.

Manullang. $1990 . \quad$ Pengukuran Produktivitas dengan Metode Nilai Tambah. Jakarta: Pusat Produktivitas Nasional.

Masyhuri. 1994. Pengembangan Agribisnis dalam Era Globalisasi. Yogyakarta: Fakultas Pertanian UGM.

Mubyarto. 1994. Pengantar Ekonomi Pertanian. Jakarta: LP3S.
Nasruddin, W. 1999. Pengantar Tataniaga Pertanian. Universitas Terbuka.

Nicholson, W. 1992. Mikroekonomi Intermediate dan Penerapannya. Jakarta: Erlangga.

Nurmedika, Marhawati M, Max Nur Alam. 2003. Analisis Pendapatan dan Nilai Tambah Keripik Nangka Pada Industri Rumah Tangga Tiara di Kota Palu [Jurnal]. Jurusan Agribisnis, Fakultas Pertanian, Universitas Tadulako, Palu.

Rahardjo, M Dawam. 1986. Transformasi Pertanian, Industrialisasi dan Kesempatan Kerja. Jakarta: Universitas Indonesia Press.

Said, Gumbira, A.dan E, Harizt Intan. 2001. Manajemen Agribisnis. Indonesia: PT. Ghalia.

Singarimbun, Masri dan Sopian Efendi. 1995. Metode Penelitian Survey. Jakarta: LP3S Indonesia.

Soeharjo, A. 1991. Konsep dan Ruang Lingkup Agroindustri kumpulan makalah

Agribisnis. Jurusan Sosial Ekonomi Pertanian. Institut Pertanian Bogor.

Soekartawi. 1990. Teori Ekonomi Produksi Dengan Pokok-pokok Bahasan Analisis Fungsi Cobb Douglas. Jakarta: Rajawali.

Soekartawi. 1995. Analisis Usaha Tani. Jakarta: UI Press.

Soekartawi.2002. Prinsip Dasar Ekonomi Pertanian Teori dan Aplikasinya. Jakarta: PT Raja Grafindo Persada.

Soekartawi. 2005 Agribisnis Teori dan Aplikasinya. Jakarta: PT Raja Grafindo Persada.

Sufanti, RD.Mely. 2000. Analisis Keragaan dan Nilai Tambah Industri Kecil Pengolahan Sari Kelapa (Nata de Coco) Serta Pengaruhnya Terhadap Lingkungan. [Skripsi] Jurusan Sosial Ekonomi, Fakultas Pertanian Universitas Padjadjaran.

Suryana, 1990. Diversifikasi Pertanian Dalam Proses Mempercepat Laju 
Pembangunan Nasional. Jakarta: Pustaka Sinar Harapan.

Tjiptono, Fandy. 2008. Strategi Pemasaran Edisi III. Yogyakarta: Andi.

Tarigan, R. 2004. Ekonomi Regional. Jakarta: Bumi Angkasa.

Usman, Husaini dan Purnomo Setiady Akbar, 2008. Metodologi Penelitian Sosial. Jakarta: PT. Bumi Aksara

Produksi Pisang Kecamatan Subang. http://www.subang.go.id/serba_serbi/bape da/SDA2011/1652a-Bab-5 pertanian.pdf [15 Agustus 2014]
Sentra Produksi Pisang di Jawa Barat. http://regionalinvestment.bkpm.go. id/newsipid/id/commodityarea.php $\underline{\text { ?ia }=32 \& \mathrm{ic}=2611} \quad[15 \quad$ Agustus 2014]

Karakteristik dan Biologi Pisang. http://www.litbang.deptan.go.id/sp ecial/publikasi/doc_hortikultura/pis ang/pisang-bagian-b.pdf $[16$ Agustus 2014] http://diperta.jabarprov.go.id/index. php/subMenu/1649 [16 Agustus 2014] 